\title{
Ellis van Creveld syndrome: An unusual presentation at birth
}

\author{
Vidisha Singh ${ }^{1}$, Alka Agrawal ${ }^{2}$, Kailash Chandra Aggarwal ${ }^{3}$ \\ From ${ }^{1}$ Post Graduate Student, ${ }^{2}$ Professor and Dean, ${ }^{3}$ Professor and Head, Department of Paediatrics, Santosh Medical College (Deemed University), \\ Ghaziabad, Uttar Pradesh, India
}

\begin{abstract}
Ellis Van Creveld, a syndrome comprising of chondrodysplasia, bilateral polydactyly of the hands with skeletal abnormalities, and congenital heart defect is a rare autosomal recessive disease. The prevalence of the disease in the world is $1 / 6000-20,000$ newborns. In the Indian population, it is difficult to estimate the exact prevalence of the disease but, it is mostly seen in the Amish population. The cardinal features are short stature, dysplastic nails and teeth, polydactyly, narrow chest, and heart defects. The crucial differentials are Jeune dystrophy, Weyers syndrome, and McKusick-Kaufman syndrome. Here, we report a neonate, born of a non-consanguineous marriage with a syndromic appearance consisting of a bell-shaped chest, polydactyly, natal teeth, and single atrium. Prognosis is related to respiratory and heart defects in the early neonatal period.
\end{abstract}

Key words: Chondroectodermal dysplasia, Single atrium, Talipes equinovarus

$\mathrm{T}$ he Ellis-Van Creveld (EVC) syndrome, also known as Chondroectodermal dysplasia is a skeletal and ectodermal dysplasia that is characterized by the narrow chest, short ribs with congenital heart defects such as Atrial septal defect with polydactyl [1]. Richard W. B. Ellis (1902-1966) and Simon van Creveld (1895-1971) were the first to report the syndrome. It is an autosomal recessive trait caused due to mutation of EVC1 or EVC2 [2].

We describe below an atypical case of EVC syndrome with single atrium, talipes equinovarus, natal teeth, and polydactyly. The reported case becomes rarer because of a single atrium as a heart defect. The syndrome usually presents with a tetrad consisting of disproportionate dwarfism, polydactyly, ectodermal dysplasia, and cardiac anomalies in $50-60 \%$ of the cases [3]. Likewise, in the case being reported, all the features were suggestive of asphyxiating thoracic dystrophy, which does not have any definitive treatment. When it is combined with a congenital heart defect such as the single atrium, survival becomes difficult.

\section{CASE REPORT}

A term male baby was bought at $2 \mathrm{~h}$ of life, a product of normal vaginal delivery at home, to a second gravida un-booked mother born out of non-consanguineous marriage. The child presented with respiratory distress and blueness of the body since birth. The

\section{Access this article online}

Received - 28 October 2021

Initial Review - 12 November 2021

Accepted - 24 December 2021

DOI: $10.32677 /$ ijcr.v7i12.3230 pregnancy was uneventful with no adverse perinatal factors. There was no history of birth anoxia. APGAR score was not known.

On examination at admission, the general condition was sick with a heart rate of $154 / \mathrm{min}$, respiratory rate of $74 / \mathrm{min}$ with severe subcostal retractions, and modified Downe's score was $5 . \mathrm{SpO}_{2}$ at room air was $82 \%$ which improved to $97 \%$ with 5 liters of oxygen by Hood. The weight recorded was $2800 \mathrm{~g}$, length $43 \mathrm{~cm}$ and head circumference was $34 \mathrm{~cm}$. The patient had dysmorphic features in form of short limbs, bell-shaped chest (Fig. 1) with polydactyly (Fig. 2a), natal teeth (Fig. 2b), and right side plantar eversion (Fig. 2c). At the time of presentation, the child threw one episode of subtle seizure which was aborted by antiepileptic administration.

The investigations were carried out following admission and the complete blood count was found normal. The C-reactive protein was negative. The serum calcium levels were $7.9 \mathrm{mg} /$ dl with potassium levels being $5.9 \mathrm{mEq} / \mathrm{L}$. Cerebrospinal fluid report was normal. Ultrasonography of the cranium did not show any evidence of hydrocephalus or intracranial bleed. Echocardiography of heart subcostal view was suggestive of a single atrial chamber (Fig. 3).

During the short stay, we offered supportive treatment by giving coverage of antibiotics prophylactically, IV fluids, and loading with phenobarbitone. Based on a constellation of phenotypical findings and echo, we reached a probable diagnosis of EVC Syndrome. A molecular study was required for definitive diagnosis which couldn't be done due to a short stay in the hospital.

Correspondence to: Dr. Kailash Chandra Aggarwal, Department of Paediatrics, Santosh Medical College (Deemed University), Ghaziabad 201 001, Uttar Pradesh, India. E-mail: kcagg1955@rediffmail.com

(C) 2022 Creative Commons Attribution-NonCommercial 4.0 International License (CC BY-NC-ND 4.0). 


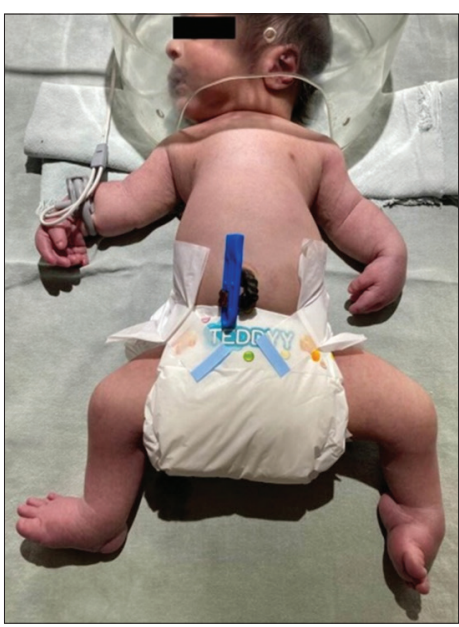

Figure 1: Neonate with narrow chest and equinovarus talipes

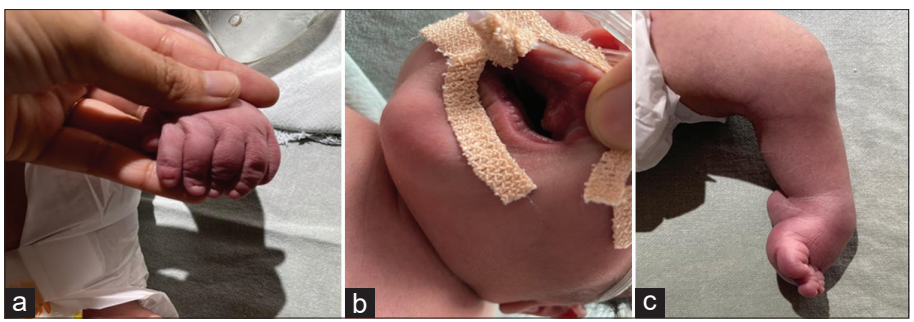

Figure 2: (a) Bilateral Polydactyly in Ellis-Van Creveld patient; (b) Anterior view of mouth showing natal teeth; (c) Right limb showing equinovarus talipes

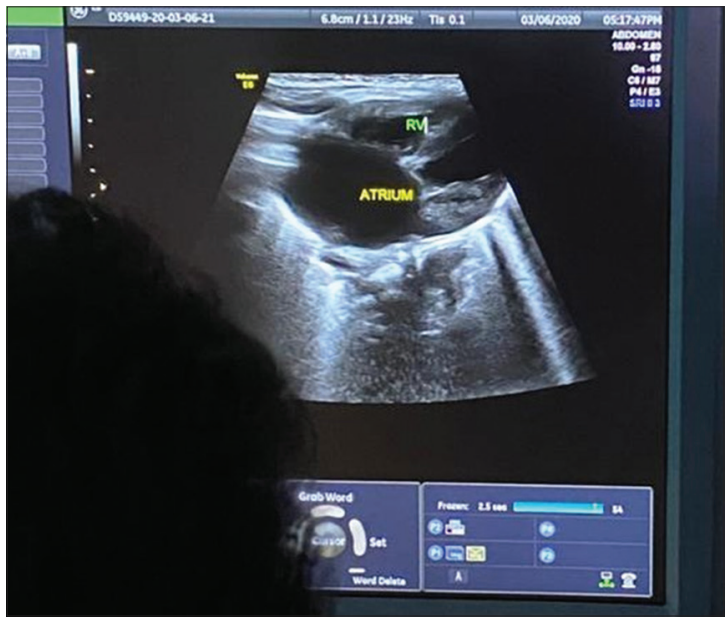

Figure 3: Absence of interatrial septum

\section{DISCUSSION}

EVC syndrome also known as chondroectodermal dysplasia, is characterized by chondrodysplasia, polydactyly, ectodermal involvement, and congenital heart defects [1,3]. Skeletal dysplasia presents with short limbs, especially in the middle and distal segments. It may be accompanied with polydactyly of hand and at times of the feet too. A close differential diagnosis is Jeune's Asphyxiating Thoracic Dystrophy which does not have heart defects [4].

The case mentioned above showed all features of the syndrome except for nail and hair dysplasia and presented with a single atrium. EVC is more prevalent in families with a history of consanguinity but the present case did not have a history of consanguineous marriage.

The disease is a rare autosomal syndrome that can be diagnosed prenatally by intrauterine growth restrictions, skeletal malformation, and cardiac defects on ultrasonography or by using chorionic villi or amniotic fluid study in early trimesters. Clinical diagnosis is done based on the symptoms and manifestations. The definitive diagnosis is by the molecular study on homozygosity for mutation in the $\mathrm{EVC}$ and $\mathrm{EVC} 2$ genes $[5,6]$.

Oral manifestations are diverse and consist of neonatal teeth, multiple frenula, and fusion of the upper lip with gingival margin. Congenital heart malformation generally consists of a defect in the mitral and tricuspid valve, patent ductus arteriosus, and ventricular septal defect [7-10]. The single atrium being the cardiac defect along with other features made the life expectancy questionable in our case $[1,11]$.

To date, there is no series of systematic follow-up for EVC syndrome, but the prognosis is related to the respiratory condition and a heart defect. Cardiac surgery at times is necessary to correct congenital heart disease. Expandable prosthetics may be used later on if the respiratory system is compromised due to thoracic insufficiency [12].

\section{CONCLUSION}

EVC syndrome has high mortality in early life due to cardiac and respiratory problems. A multidisciplinary team approach is always advised which includes a cardiologist, a pediatrician, an orthopedic, a prosthodontist, an oral and maxillofacial surgeon, an orthodontist for management and rehabilitation of such patients. In this case, the parents were upright about the rare disorder which has a bad prognosis and corrective surgery for heart defects.

\section{REFERENCES}

1. Kurian K, Shanmugam S, Vardah TH, Gupta S. Chondroectodermal dysplasia (Ellis van Creveld syndrome): A report of three cases with review of literature. Indian J Dent Res 2007;18:31-4.

2. Muensterer OJ, Berdon W, McManus C, Oestreich A, Lachman RS, Cohen MM, et al. Ellis-van Creveld syndrome: Its history. Pediatr Radiol 2013;43:1030-6.

3. Sasalawad SS, Hugar SM, Poonacha KS, Mallikarjuna R. Ellis-van Creveld syndrome. BMJ Case Rep 2013;2013:bcr2013009463.

4. Keppler-Noreuil KM, Adam MP, Welch J, Muilenburg A, Willing MC. Clinical insights gained from eight new cases and review of reported cases with Jeune syndrome (asphyxiating thoracic dystrophy). Am J Med Genet Part A 2011;155:1021-32.

5. Tompson SW, Ruiz-Perez VL, Blair HJ, Barton S, Navarro V, Robson JL, et al. Sequencing EVC and EVC2 identifies mutations in two-thirds of Ellisvan Creveld syndrome patients. Hum Genet 2007;120:663-70.

6. Baujat G, Le Merrer M. Ellis-van creveld syndrome. Orphanet J Rare Dis 2007;2:1-5.

7. Ghassemi M, Goodarzi A, Seirafianpour F, Mozafarpoor S, Ziaeifar E. Rare clinical features of the Ellis van Creveld syndrome: A case report and literature review. Dermatol Ther 2021;34:e14664.

8. Dekker MC, Sadiq AM, Jusabani MA, Mdavire VJ, Baas F, Morton DH, et al. Ellis-van Creveld syndrome in a patient from Tanzania. Am J Med Genet Part A 2019;179:2034-8.

9. Weiner DS, Jonah D, Leighley B, Dicintio MS, Morton DH, Kopits S. Orthopaedic manifestations of chondroectodermal dysplasia: The Ellis-van Creveld syndrome. J Child Orthop 2013;7:465-76. 
10. Scurlock D, Ostler D, Nguyen A, Wahed A. Ellis-van Creveld syndrome and dyserythropoiesis. Arch Pathol Lab Med 2005;129:680-2.

11. Shilpy S, Nikhil M, Samir D. Ellis van creveld syndrome. J Indian Soc Pedod Prev Dent 2007;25(Suppl 5):5-7.

12. Kumar A, Sharma S, Sharma M, Bhargava K. Common atrium with unusual electrocardiogram in Ellis-Van Creveld syndrome: A case report. Hear India 2015;3:103.
Funding: None; Conflicts of Interest: None Stated.

How to cite this article: Singh V, Agrawal A, Aggarwal KC. Ellis van Creveld syndrome: An unusual presentation at birth. Indian J Case Reports. 2021;7(12):538-540. 